\title{
Saúde mental e terapia ocupacional: a construção de um projeto terapêutico singular
}

\author{
Sabrina Ferigato ${ }^{a}$, Michelle Chanchetti Silva ${ }^{b, c}$ \\ aDepartamento de Terapia Ocupacional, Universidade Federal de São Carlos - UFSCar, São Carlos, SP, Brasil. \\ bUniversidade Estadual de Campinas - UNICAMP, Campinas, SP, Brasil. \\ ${ }^{\mathrm{c}}$ Centro de Atenção Psicossocial Novo Tempo, Campinas, SP, Brasil.
}

\begin{abstract}
Resumo: Introdução: Este texto apresenta a construção de um Projeto Terapêutico Singular de uma pessoa com transtorno mental inserida em um Centro de Atenção Psicossocial (CAPS) de Campinas-SP. Método: Daremos especial enfoque às costuras e redes produzidas a partir da intervenção do núcleo da Terapia Ocupacional, entremeada pelas ações do campo da Saúde Mental. Para isso, utilizaremos como método de produção do texto o relato de experiência à luz de referências teóricas da Clínica Psicossocial e da Saúde Coletiva. Resultado: Como resultado, elucidaremos algumas funções que a Terapia Ocupacional e o uso de atividades podem cumprir em um CAPS e na construção de um plano terapêutico interdisciplinar. Conclusão: Essa construção nos dá subsídios para refletir sobre nosso processo de trabalho na saúde mental com o intuito de elucidar aspectos específicos da clínica terapêutica ocupacional no cuidado de pessoas com transtornos mentais, além de evidenciar funções que a rede de atenção psicossocial pode exercer no contexto mais amplo da rede de saúde.
\end{abstract}

Palavras-chave: Terapia Ocupacional, Atenção à Saúde, Saúde Mental.

\section{Mental health and occupational therapy: building a singular therapeutic project}

\begin{abstract}
Introduction: This text presents the construction of a Therapeutic Project Single of a person with mental disorder admitted in a Psychosocial Care Center of Campinas-SP. Method: We will give special focus on seams and networks produced from the intervention of the Occupational Therapy core, interspersed by the mental health field actions. Thus, we will use as text production method the experience report in the light of theoretical references of Psychosocial Clinical and Public Health. Results: As a result, we will elucidate some functions that Occupational Therapy and the use of activities can generate in a Psychosocial Care Center and in the development of an interdisciplinary treatment plan. Conclusion: This development gives us subsidies to reflect on our working process in mental health with a view to clarify specific aspects of clinical occupational therapy towards the care of people with mental disorders, in addition to evidencing functions that psychosocial care network can exercise in the broader context of health network.
\end{abstract}

Keywords: Occupational Therapy, Health Care, Mental Health. 


\section{Introdução}

Esse texto pretende apresentar o relato de uma experiência de intervenção terapêutica ocupacional para evidenciar aspectos relevantes sobre a clínica do CAPS (Centro de Atençâo Psicossocial) e do núcleo da terapia ocupacional no campo da saúde mental.

Apresentar um atendimento em terapia ocupacional em um CAPS é apresentar a potência de um núcleo profissional que necessariamente se articula em rede, ou seja, é também apresentar a construção de um Projeto Terapêutico Singular (PTS) de forma compartilhada, interdisciplinar e territorializada.

No contexto da Reforma Psiquiátrica, o CAPS constitui-se como um equipamento inserido numa rede de Atenção Psicossocial, que tem como papel estratégico a articulaçáo e tecimento de redes, regulação e organização do cuidado em Saúde Mental de um dado território.

Do ponto de vista da assistência, trata-se de um serviço "porta-aberta", com o objetivo de oferecer cuidado integral às pessoas que apresentem transtornos mentais severos e persistentes. Esse suporte visa oferecer cuidado clínico e de reabilitação, com estratégias alternativas ao modelo manicomial, contribuindo para a minimização do número de internaçôes e ressignificação da relação do sujeito e da sociedade com a doença. Além disso, observa-se o imperativo de construçáo de um olhar ampliado sobre o processo saúde-doença-intervenção, investindo no protagonismo dos sujeitos com sofrimento psíquico e na ampliação do coeficiente de autonomia de indivíduos e coletivos para o exercício da cidadania.

Depois de mais de duas décadas de início da Reforma Psiquiátrica, faz-se necessária a reafirmação dos princípios ético-clínico-políticos que a norteiam, especialmente a partir da difusão e do fortalecimento de suas práticas. Uma das maneiras de promover esse fortalecimento é a divulgação de suas experiências concretas, com ênfase na explanação das mudanças efetivas que esse novo modelo de atençáo pode promover no encontro entre trabalhadores e usuários de saúde. Nesse sentido, a socialização de Projetos Terapêuticos Singulares (PTS) pode funcionar como um analisador importante desse novo modelo, bem como de suas tecnologias de cuidados: a clínica interdisciplinar, o trabalho em rede, a atençáo aos familiares, ações no território, etc.

Para Campos (2005), o PTS é uma ferramenta para a gestão da clínica que engloba um conjunto de propostas, de condutas terapêuticas articuladas para um sujeito individual ou coletivo, resultado da discussáo coletiva de uma equipe interdisciplinar específica ou em rede.

A escolha do PTS como um intercessor para a produção deste relato se dá no sentido de utilizar esse dispositivo como objeto de análise, ou seja, não se trata da construção do projeto em si, mas de sua utilização como disparador para discussóes sobre as redes que se podem construir em busca de resolubilidade para as açóes das equipes (VASCONCELOS; JORGE, 2013).

No relato do PTS escolhido para este texto, daremos ênfase a um dos pontos dessa construção, que foi a intervenção em terapia ocupacional, não só por ser essa a via principal de inserção das autoras no caso, mas por ter sido a Terapia Ocupacional um importante dispositivo para a construçáo de redes e para o fortalecimento do Projeto Terapêutico Singular deste caso em especial.

Para a sistematização deste processo em texto, utilizaremos a metodologia de relato de experiência a partir dos referenciais teóricos da Clínica Psicossocial ${ }^{1}$ em diálogo com a corrente da Saúde Coletiva denominada "Em defesa da vida"

Utilizaremos como fonte de dados para a produção deste relato a análise documental dos registros em prontuário e a experiência clínica vivida pelas autoras.

\section{Da construção do caso à produção de causos}

José Carlos ${ }^{3}$ nasceu em 64, em Campinas, em uma família já composta por três filhos. Refere que até os sete anos de idade, sua vida transcorreu normalmente, sem nenhum evento que ele considere significativo. Nessa idade, seu pai saiu de casa e, por isso, sua família passou por sérias privaçôes financeiras e dificuldades relacionais. Ele foi obrigado a sair de um colégio particular e passar a estudar em uma escola pública, na qual, segundo relato, ele era o único garoto loiro, chamado de branquelo pelas outras crianças. Nessa mesma época, seu irmão, com então 8 anos, fica cego em decorrência de um tumor cerebral. José passa a ser a figura cuidadora e companheira desse irmão, até a presente data.

Aos 16 anos, seu pai retorna para casa, José ingressa num curso técnico e consegue seu primeiro emprego como torneiro mecânico. Até 1981, ele passa a "levar uma vida de muito trabalho e muita agitação", com muito serviço e baladas noturnas. Além disso, praticava aulas de karatê e outros cursos profissionalizantes. 
Aos 20 anos, ele vive um grande amor, mas é abandonado três anos depois. No mesmo ano do fim do namoro, José é informado de que teria que se submeter a uma cirurgia de varicocele (a formação patológica de varizes na região do escroto). Nesse momento, relata que passa a viver a sensaçáo de que terá seu pênis amputado e passa a desenvolver comportamentos persecutórios no trabalho e com a família.

Um ano depois, ele faz uma importante tentativa de suicídio, chocando sua moto contra um carro em alta velocidade. Nesse episódio, permanece alguns dias na UTI, com múltiplas fraturas no corpo.

A partir de então, os sintomas psicóticos passaram a se intensificar. Em menos de 1 ano, ele foi afastado pelo Instituto Nacional do Seguro Social (INSS) por invalidez (aos 26 anos de idade) e sofreu sua primeira de muitas internaçôes psiquiátricas. Nesse momento, José alega ter descoberto que não nasceu para o mundo do trabalho e completa:

Declaro que entrego os pontos, jogo a toalha; entrego-me às mãos de fada das enfermeiras, às mãos cirurgiãs dos psiquiatras e à mão grande da polícia - entrei no caminho sem volta da psiquiatria [...] (José Carlos).

Até completar 32 anos José vivia períodos de longas internaçôes e retornos breves para casa. Refere ter sido sujeito de intervençóes mais diversas, incluindo a eletroconvulsoterapia, o que, em sua análise, fez com que ele desenvolvesse

Poderes milagrosos de conhecer espaços de morte estando vivo [...] (José Carlos).

Aos 33 anos, José refere ter "[...] aceitado a condição de seus pais o julgarem louco [...]" e inicia seu primeiro acompanhamento junto à Unidade Básica de Saúde, na qual recebeu acompanhamento médico-medicamentoso até 2005, quando é encaminhado para um CAPS-III.

Na primeira intervenção realizada pelos profissionais do CAPS, em visita domiciliar, ele é encontrado em estado precário de higiene, há meses sem sair do quarto, com a sexualidade exacerbada, pouco contato, com delírios de grandeza, de perseguição e alucinaçóes auditivas.

Desde o início do tratamento, a família de José, sempre se mostrou muito afetiva, ao mesmo tempo em que o tratava como uma criança que precisava de cuidado intensivo e controle em tempo integral.

Durante os primeiros anos de inserção no serviço, o acompanhamento de José era muito pontual, até que por solicitação da profissional de referência que o acompanhava, ele é inserido no atelier de Terapia Ocupacional que acontecia semanalmente.

José encontra nesse espaço um importante ambiente para expressão de suas angústias e delírios, especialmente através da pintura e da escrita. A compulsão de José pelas atividades, expressada nos ateliês, indicou a necessidade de somar ao atendimento grupal um acompanhamento individual em Terapia Ocupacional. O psicólogo da instituição também avaliou a necessidade de atendê-lo em grupo de psicoterapia. Nascia ali, a possibilidade de estreitar o vínculo dos profissionais com o usuário e de produzir novos agenciamentos em rede.

Com esse conjunto de açôes, José passa então a criar vínculos afetivos com outros usuários do CAPS, a produzir um sentido compartilhável em relaçáo aos seus delírios, elaborar conflitos, construir uma agenda própria, agir no mundo, se comunicar melhor.

Percebendo a gradativa melhora de José, seus familiares começaram a participar dos grupos de família, reconhecer seus potenciais e se posicionarem de outra maneira em relação a suas limitações.

Depois de alguns meses de investimento por parte da equipe, José já se apresentava bem melhor em relação à sintomatologia psiquiátrica, porém queixava-se de diversos efeitos colaterais da medicaçáo. Em parte, esses efeitos eram identificados nos espaços de intervençáo terapêutica ocupacional, em que ele era convidado a agir e interagir.

Nesse momento José decide que não aceitará mais tomar a medicação. Isso causa uma resistência inicial por parte dos profissionais, mas, considerando o processo que se realizava, a equipe decide sustentar a possibilidade dessa negociação com seu psiquiatra que não compartilha dessa decisão, ao mesmo tempo em que não abre espaço para o diálogo.

Essa postura causou diversas discussóes em equipe, sobre qual era nossa função para com José e demais usuários, sobre a complexidade entre as responsabilidades da equipe e os direitos dos usuários da saúde mental. Analisávamos criticamente se o que fazíamos era terapêutica ou controle da vida de alguns usuários.

Tentamos incluir e ampliar a discussão sobre a medicação, para além da redução sintomatológica; buscamos construir junto à equipe a ideia de que a medicação tem também o papel de estabelecer condição de relaçáo diferente entre o paciente e seu problema, entre paciente e equipe, paciente e a vida. Nessa linha, a intervenção farmacológica precisa ter uma profunda congruência e integração com a construção do PTS do usuário (SARACENO; ASIOLI; TOGNONI, 2001). 
Depois de algumas reunióes, outra médica assumiu o caso e a equipe apostou em bancar com o usuário e sua família a sua decisão sobre o que fazer com seu tratamento e com seu corpo. Intensificou-se o acompanhamento no CAPS durante o momento gradativo de retirada da medicaçáo e, aos poucos, suas queixas em relação aos efeitos colaterais como impotência, rigidez, sialorréia, etc., foram diminuindo.

Ele ficou por alguns meses muito bem, começou a namorar e a frequentar outras atividades do CAPS. Essa aposta foi extremamente importante para a confiança e vinculação de José Carlos ao serviço (que legitimou seu desejo) e para o desenvolvimento de relaçôes afetivas em várias outras esferas da sua vida.

A vivência de algumas situaçóes estressantes no CAPS e em sua casa (o suicídio de uma de suas amigas do CAPS e a piora de saúde do pai) associada ao tempo prolongado sem medicação foram alguns dos elementos que contribuíram para que José Carlos voltasse a apresentar quadros importantes de delírios, insônia e euforia.

Intensificamos os atendimentos individuais em terapia ocupacional, especialmente por que, em momentos de desorganização discursiva, o uso de atividades como instrumento de intervençáo proporcionava significativa melhora e possibilidade de expressão de conflitos que, para José, não eram possíveis de serem colocados em palavras.

Para Castro, Lima e Brunello (2001), as atividades humanas são constituídas por um conjunto de açóes que apresentam qualidades, demandam capacidades, materialidade e ativam processos. A linguagem da ação é um dos muitos modos de conhecer a si mesmo, o outro, o mundo, o espaço e o tempo em que vivemos e a nossa cultura.

$\mathrm{O}$ que se estabelece no decorrer de um atendimento de terapia ocupacional é um campo de experimentação de si e do mundo. Não se trata apenas do confronto com uma nova matéria de expressão, mas a constituição de complexos de subjetivação. $\mathrm{O}$ agenciamento sujeito-atividade-trocas-múltiplas oferece diversificadas formas de composição de uma corporeidade existencial, produzindo processos de ressingularização (GUATTARI, 2006).

Naquele momento do tratamento de José, a atividade da escrita passa a ocupar a centralidade da intervençáo de terapia ocupacional. Atendimentos a fio eram destinados para suas narrativas e para a terapeuta ocupacional digitar relatos de suas experiências delirantes, relatos de suas experiências de vida. Nesse processo, José se emocionava, se enfurecia, chorava, ria e as intervençóes terapêuticas eram realizadas.
Muitas vezes, ao ler suas histórias, José se dava conta de sua desorganização, jogava o papel fora e começava a mesma história novamente. Nesses momentos, a função de suporte oferecido pela terapeuta ocupacional era fundamental. Segundo Knobloch (1998), a postura de suporte profissional se dá no sentido literal de suportar o insuportável, de afirmar a realidade do acontecimento da crise, no sentido de sustentar sua força destrutiva, para que ela encontre destinos mais criativos para o sujeito.

Com o tempo, as narrativas passavam a ter começo, meio e fim, transmitindo histórias compreensíveis, com sentidos mais compartilhados, mesmo que não normatizados. Mesmo na expressão de seus delírios, era possível ser construído um sentido não apenas para quem narrava, mas para quem lia e ouvia suas histórias.

Quando relatávamos essa experiência, ficávamos sempre na dúvida se descreveríamos seus causos como Estórias (com E) ou Histórias (com H). Estória é um neologismo, para designar a narrativa popular, o conto tradicional, fictício. Esse termo difere claramente da noção de História, pelo primeiro ser algo "inventado" e o segundo algo verídico, factual. Outra forma de distinção é escrever "história" (com caixa baixa ou minúscula) e "História" (com caixa alta ou maiúscula). O primeiro termo significa narrativa e o segundo refere-se à Ciência que estuda o homem no tempo.

A dúvida era instaurada pelo fato de se tratarem de experiências delirantes, porém vivenciadas como reais e com verdadeiros fatores de realidade para o usuário. O Hibridismo de loucura e "realidade" - identificaçáo e estranhamento estavam sempre presentes. No fim, por considerar eticamente que a experiência do usuário era o que dava valor a esses escritos, passamos a nos referir a elas como as histórias do Zé, afirmando o fator real do delírio.

Com o tempo, ele passou a ler seus 'causos' que foram compilados em um texto intitulado " $E m$ dois minutos, quase a eternidade". Essa leitura era semanalmente feita para outros profissionais e usuários em espaço de convívio e produzia um efeito positivo e provocativo nas pessoas, ora de emoção, ora de riso ou estranhamento.

Com o tempo, alguns usuários ficavam à espreita, aguardando o fim das sessóes de terapia ocupacional, faziam uma roda e José lia a história da semana.

Posteriormente, essa produçáo ultrapassou os limites institucionais e suas histórias foram aceitas para serem expostas na sessão de 'Prosas e Poesias' da Conferência Municipal de Saúde de Campinas. Suas narrativas também foram publicizadas em uma 
exposição literária realizada em uma praça pública. Essas intervençôes

[...] produzem efeitos nos expositores e no público, transformando as relações entre eles. [...] Processo e produto, neste contexto, passam a formar uma unidade de sentido [...] (CASTRO; LIMA; BRUNELLO, 2001, p. 53).

Aos poucos, a intervenção em terapia ocupacional e a voz de José, que antes ocupavam pouca centralidade em seu tratamento, passam a sair do setting protegido e ganhar a instituição, ganhar espaços na cidade.

Interessante apontar que, como afirma Lima (2004), os produtos da intervenção terapêutica, aos poucos, vão se desprendendo de sua origem institucional para fazer seu percurso no universo cultural e ver de que forma eles possibilitam estranhamentos e novas afetaçóes, instaurando novos regimes de sensibilidade. Abre-se espaço para criaçôes "loucas", para a importância de uma escuta atenta e interessada por essas produçóes, para a geração de conflito no espaço institucional e fora dele.

Neste sentido, a atividade funcionou não apenas facilitando a expressão do sofrimento, sua objetivação e elaboração, mas agenciou novos sentidos para uma subjetivação delirante, colocou essa expressão em diálogo com um grupo e com a cidade, proporcionando outros espaços de inserção. Em contextos como esse, a pessoa "fala" em seu fazer, mas também "é falado" por ele, no sentido em que somos portadores de nossa própria história construída na relação com os outros (FERIGATO; SY; CARVALHO, 2011).

Entre essas histórias, suas vivências da época de motoqueiro estavam sempre muito presentes. Ele falava da sensação de liberdade que o vento no rosto causava. Muitos de seus delírios estavam vinculados à motocicleta, que havia sido no passado seu instrumento para a tentativa de suicídio. A ideia de voltar a andar de moto era inviabilizada por sua família e pela perda há anos de sua carteira de motorista.

Foi então que pensamos na alternativa de uma bicicleta fazer, em parte, José reviver algumas dessas emoçôes. Disponibilizamos uma bicicleta de um profissional por um preço simbólico no bazar do CAPS e ele a adquiriu. Foram necessários apenas dois passeios com acompanhamento da T.O. Então ele transformou a bicicleta em algo muito diferente do que ela era no início, incrementando-a com rádio, penduricalhos e adesivos. Iniciou com ela uma nova exploração no território. Para os vizinhos ele já não era mais o 'Zé doido', era o 'Zé da bicicleta'. Essa composiçáo corpo-bicicleta-rua criou novos territórios existenciais (DELEUZE; GUATTARI,
1997) e novas possibilidades de encontro: com o trânsito, com o bicicleteiro, com os frentistas dos postos de gasolina, com os clientes do bar da esquina. Tudo isso, traçado no caminho de loucas pedaladas, permitindo a ele ser reconhecido e se reconhecer por outros fazeres (FERIGATO, 2013; CASTRO; LIMA; BRUNELLO, 2001).

\section{Novos encontros conectando novas possibilidades}

Passados dois anos, a terapeuta ocupacional que o acompanhava nessa jornada se desligou do CAPS e foi realizada gradativamente a transferência do caso para outra T.O. escolhida por José (esse relato é narrado por essas duas terapeutas ocupacionais).

Desde então, os atendimentos acontecem semanalmente, ora no setting do CAPS, ora em sua residência ou pela cidade. As atividades escolhidas são de acordo com as demandas do sujeito e do processo terapêutico, com enfoque nos pressupostos da terapia ocupacional como produçáo de vida. A ação terapêutica busca apontar para a construção de uma metodologia de intervençáo em Terapia Ocupacional que pressupóe um alinhamento rigoroso entre a clínica, a proliferação de vida e os processos de subjetivação (LIMA et al., 2009).

Nesse sentido,

Conversar, escrever, cozinhar, pintar, passear etc., são modos de cuidar/estar/escutar/acolher o sofrimento, a loucura e dar-lhes tempo e matéria para que, filmando, passeando, cozinhando, cantando se recriem maneiras de estar no mundo... As atividades, o fazer humano, são tomadas como territórios, potência e matéria de criação, expressão de modos de existir, de novos começos e da própria fabricação de mundos [...] (QUARENTEI, 1994, p. 197).

Mais recentemente, surge o interesse de José resgatar o contato com pessoas que passaram por sua vida e para esse fim solicita aprender a usar a internet. Durante os atendimentos, passamos pelas questôes mais básicas de informática como aprender a ligar/desligar o computador a conversas de como algo que ele queria dizer poderia ser transmitido online. Conversávamos sobre o virtual e o real e suas percepçóes acerca destes mundos e sua vida, sobre os sentidos e as marcas que ficaram em sua vida à medida que ele produzia cartas a serem enviadas por $e$-mail.

Ele descobre como pesquisar assuntos de seu interesse, em sites de busca e de vídeos... Assiste a clipes 
de suas bandas favoritas e conta suas experiências da juventude. Faz novas conexóes com o mundo e com seu mundo.

Mas a virtualidade e pequenos avanços na inclusão digital não eram o bastante, José queria ir além... Queria ultrapassar os limites que suas pedaladas e o computador permitia. Queria acompanhar sua namorada aos finais de semana em passeios, andar de ônibus, ir "à cidade" - o que há décadas não fazia sem a companhia de alguém da família.

Investir em atividades dessa natureza seria uma aposta de produzir mudanças da percepçáo que o outro tem de si, uma possibilidade para diminuir estigmas e gerar novos encontros entre o sujeito e seu sócio (FERIGATO, 2013).

Paralelo a isso, José trazia certo incômodo com o uso do dinheiro de seu benefício nas reformas da casa e pede ajuda para conversar com a família sobre seus direitos em relaçáo ao uso de seu dinheiro. Realizamos a conversa, a família foi receptiva. Fica combinado que num primeiro momento ele receberia apoio da terapeuta para planejamento e uso do dinheiro, além de acompanhamento nas compras iniciais por meio de Acompanhamento Terapêutico (A.T.).

José, muitas vezes, trazia a sensação de que a família ainda não confiava nele, e ele, por sua vez, não conseguia expressar o que pensava para os familiares. O investimento nessa relação também foi alvo de intervenção, realizada por um período ainda em curso.

Essas foram apenas algumas etapas da construção do Projeto Terapêutico de José. Em consonância com a proposta de um plano de intervenção terapêutica ocupacional, a construçáo do Projeto Terapêutico Singular produziu um movimento de coprodução e de cogestão do processo terapêutico de um Sujeito Singular, em situação de vulnerabilidade. As intervençóes foram construídas levando em conta que esse mesmo sujeito está inserido em um contexto social, cultural, familiar e em um território (OLIVEIRA, 2010a).

A coproduçấo de autonomia, um dos objetivos históricos da terapia ocupacional e uma das propostas do PTS, foi "medida" não a partir de uma pretensão de cura, mas a partir do ganho dos sujeitos, em termos de gradientes, de capacidade de lidar com os próprios problemas e potencialidades, com seu contexto sociorrelacional, em relação a uma situação anterior (OLIVEIRA, 2010b).

Avaliamos que, hoje, mesmo com o diagnóstico de esquizofrenia, José é mais protagonista de sua vida e apresenta aumento do poder contratual, dos laços sociais e afetivos, com significativa qualificação de múltiplos aspectos do seu cotidiano, por exemplo, maior autonomia nas relações familiares, nas atividades da vida diária e vida prática.

Com os avanços alcançados, discutimos com ele como construir um PTS que náo fique restrito à permanência no CAPS, que explore formas de circulação pelo território que lhe façam sentido. Atualmente parte desse processo acontece no CAPS (grupo de referência, acolhimento, atendimento de T.O.) e outra parte se direciona com a participaçáo de atividades no território (Centro de Convivência, Acompanhamento Terapêutico, e a exploração da cidade). José Carlos tem mantido a escolha de não fazer uso de medicaçáo e a equipe tem respeitado este posicionamento.

Atualmente José circula sozinho pela cidade, comunica-se com outras pessoas de acordo com sua necessidade e possibilidades, tem amigos, faz compras, vai a parques e ao shopping com a namorada, se inseriu, junto com seu irmão deficiente visual, nas atividades de um Centro de Convivência.

Uma abordagem como essa parte de princípios ético-clínicos que, de acordo com Nicácio (1994), não se identificam com a psiquiatria ortodoxa, tampouco com propostas de elogio à loucura: trata-se de atravessar os campos de saúde e doença, de traçar uma profunda ruptura com modelos clínicos hegemônicos ou outras formas de codificação do sofrimento, de se confrontar com os valores culturais que atribuem desvalor à diversidade, à diferença, à ruptura das normas.

\section{Conclusão}

Ao narrarmos a construção de um atendimento de T.O. articulado a um Projeto Terapêutico Singular construído de forma participativa, interdisciplinar e em rede, buscamos evidenciar possíveis transformaçóes que a reabilitação psicossocial pode produzir na vida de pessoas com transtornos mentais. Neste contexto, buscamos elucidar algumas funçóes que a Terapia Ocupacional pode cumprir em um CAPS, constituindo um trabalho de caráter a um só tempo expressivo, construtivo e inclusivo; ampliando a capacidade de sujeitos individuais e coletivos serem afetados pela experiência e passarem a agir ativamente na produção de novos caminhos, na construção de casos e causos num cotidiano reinventado (FERIGATO, 2013). Além disso, procuramos explorar ações que podem ser realizadas nos CAPS para além da clínica stricto sensu, realizando apostas clínicas que sáo sempre também uma aposta ética e política. Ética, 
pela possibilidade de uma intervençáo nas relaçóes que um sujeito (trabalhador/usuário) estabelece consigo próprio e com o mundo e, finalmente, uma aposta política, por sua sustentação institucional de afirmaçáo da saúde como um direito e um modo de viver a ser construído e não dado prescritivamente.

Nesse sentido, valorizamos a clínica psicossocial por sua potência de produzir desvios, pela possibilidade gerada de criar um espaço de jogo, para que uma singularidade possa inscrever-se no mundo a partir de relaçôes orientadas não apenas pela objetividade científica, psiquiátrica e moral, mas por variáveis subjetivas como o desejo, o afeto e a liberdade.

A escolha deste caso se deu no sentido de afirmar a legitimidade dessa clínica a partir de ferramentas coconstruídas como a interdisciplinaridade, o Projeto Terapêutico Singular, a equipe de referência, as oficinas, os atendimentos individuais e os Acompanhamentos Terapêuticos (ATs).

José, com seus causos e conexóes, atualiza os benefícios do acompanhamento em Terapia Ocupacional, de um olhar ampliado, do funcionamento coerente e conflituoso de uma equipe interdisciplinar sobre o processo de adoecimento, com intervençôes que não considerem somente $\mathrm{o}$ adoecimento, mas que façam investimentos em projetos terapêuticos atrelados ao cotidiano e aos projetos de vida das pessoas.

José, sua família e nós reconhecemos que a inserção no CAPS, o acompanhamento em terapia ocupacional e demais intervençôes do serviço foram importantes para produzir novos sentidos às relaçôes estabelecidas em família, para interromper o fluxo de internaçôes, reduzir os efeitos da segregação social, ampliar o exercício de sua cidadania.

Com essas intervençôes, observou-se importante impacto e mudanças significativas do ponto de vista da ampliação das possibilidades de encontro com a vida.

20 anos de isolamento dentro de casa, internaçōes edopamento, ai chega o CAPS, a T.O. e o Zésolta a franga! (José Carlos).

Por isso, acreditamos na importância de superar o modelo de tratamento baseado em intervençóes manicomiais ou puramente biomédicas e apostar em intervençôes criativas, que invistam no movimento da vida. Inventar novas práticas e conceitos para lidar com a loucura que náo sejam instrumentos de exclusão e controle, mas de produção devida (QUARENTEI, 1994; LIMA et al., 2009).

Consideramos que o relato de casos como este, também evidencia alguns desafios importantes: É importante estarmos atentos ao modo de construção e reavaliação dos PTS, pois, muitas vezes, com a intenção de construir estratégias de produção de cuidado, podemos produzir intervençôes que funcionem como estratégias de controle e disciplinarização da vida.

Observamos que, muitas vezes, questôes das vidas dos sujeitos passam, ficam e/ou terminam no CAPS, como se este pudesse responder por todas as questôes do cotidiano do usuário. $\mathrm{O}$ mesmo pode acontecer com terapias ocupacionais institucionalizadas: a prescrição de atividades, o uso de atividades para adaptar, normatizar ou disciplinar corpos e vidas.

Por isso, afirmamos que fazer terapia ocupacional não se trata de construir modelos, receitas ou indicaçóes de atividades, mas construir com cada usuário sua trajetória singular,

[...] uma forma de sair das malhas aprisionantes de uma vida relegada a espaços muito restritos e estreitos. Trata-se de ampliar a vida, buscar interlocuçóes, conexóes, favorecer encontros, possibilitar trânsitos novos [...] (CASTRO; LIMA; BRUNELLO, 2001, p. 57)

e, especialmente, possibilitar o reconhecimento de direitos - "[...] direito de escolha, direito a se reconhecer como um sujeito que faz e que pensa, que assina sua obra, que é agente criador e transformador [...]" (SILVA; CARRARO, 2014, p. 239).

Desta forma, independentemente dos diferentes sentidos que a terapia ocupacional possa produzir para diferentes sujeitos, sua eficácia comprometida com a liberdade reside fundamentalmente na dimensão da passagem, na potencialidade que o encontro entre sujeitos com diferentes fazeres possui de dar passagem a novos sentidos de existência. $\mathrm{O}$ sentido é o fenômeno de passagem de um lugar existencial para outro. De esquizofrênico para contador de histórias, de Zé louco para Zé da bicicleta...

\section{Referências}

CAMPOS, G. W. S. A saúde pública e a defesa da vida. São Paulo: Hucitec, 1991.

CAMPOS, G. W. S. Um método para análise e co-gestão de coletivos. São Paulo: Hucitec, 2005.

CARVALHO, S. R. Saúde coletiva e promoção da saúde: sujeito e mudança. São Paulo: Hucitec, 2005.

CASTRO, E. D.; LIMA, E. A.; BRUNELLO, M. I. B. Atividades humanas e terapia ocupacional. In: CARLO, M. M. R. P.; BARTALOTTI, C. C. (Org.). Terapia Ocupacional no Brasil: fundamentos e perspectivas. São Paulo: Plexus, 2001. p. 41-59.

COSTA-ROSA, A.; LUZIO, C. A.; YASUI, S. Atençāo Psicossocial: rumo a um novo paradigma na Saúde Mental Coletiva. In: AMARANTE, P. (Org.). Arquivos de 
saúde mental e atenção psicossocial. Rio de Janeiro: Nau, 2003. p. 13-44.

DELEUZE, G.; GUATTARI, F. Mil Platôs: capitalismo e esquizofrenia. Rio de Janeiro: Edições 34, 1997.

FERIGATO, S. H. Cartografia dos Centros de Convivência de Campinas: produzindo Redes de Encontros. 2013. 320 f. Tese (Doutorado em Saúde Coletiva) - Universidade Estadual de Campinas, Campinas, 2013.

FERIGATO, S.; SY, A.; CARVALHO, S. R. Explorando lãs fronteras entre la Clínica y el Arte: relato de una experiência junto al Frente de Artistas del Borda. Salud Colectiva, Buenos Aires, v. 7, n. 3, p. 347-363, 2011. http://dx.doi.org/10.18294/sc.2011.270.

GUATTARI, F. Caosmose: um novo paradigma estético. São Paulo: Edições 34, 2006.

KNOBLOCH, F. O tempo do traumático. São Paulo: Educ, 1998.

LIMA, E. A. Oficinas, laboratórios, ateliês, grupos de atividades: dispositivos para uma clínica atravessada pela criação In: COSTA, C. M.; FIGUEIREDO, A. C. Oficinas terapêuticas em saúde mental: sujeito, produçáo e cidadania. Rio de Janeiro: Contra Capa, 2004. p. 59-81.

LIMA, E. M. F. A. et al. PACTO adolescentes: arte e corpo na invenção de dispositivos em terapia ocupacional para produção de vida e saúde na adolescência. Revista de Terapia Ocupacional da Universidade de São Paulo, São Paulo, v. 20, n. 3, p. 157-163, 2009.

MERHY, E. E.; CECÍlIO, L. C.; NOGUEIRA, F. R. C. Por um modelo técnico assistencial da política de
Saúde em defesa da vida: contribuição para as Conferências de Saúde. Revista Saúde em Debate, Rio de Janeiro, v. 33, p. 83-89, 1991.

NICÁCIO, M. F. O processo de transformação da saúde mental em Santos: desconstrução de saberes, instituiçóes e cultura. 1994. 155 f. Dissertação (Mestrado em Ciências Sociais) - Pontifícia Universidade Católica de São Paulo, São Paulo, 1994.

OLIVEIRA, G. N. O projeto Terapêutico Singular. In: CAMPOS, G. W. S.; GUERRERO, A. V. P. (Org.). Manual de práticas de atenção básica: saúde ampliada e compartilhada. São Paulo: Hucitec, 2010a. p. 283-297.

OLIVEIRA, G. N. O projeto terapêutico e a mudança nos modos de produzir saúde. São Paulo: Hucitec, $2010 \mathrm{~b}$.

QUARENTEI, M. S. Atividades: territórios para a expressão e criação de afetos. Boletim de Psiquiatria, São Paulo, v. 27, n. 1, p. 26-27, 1994.

SARACENO, B.; ASIOLI, F.; TOGNONI, G. Manual de saúde mental. São Paulo: Hucitec, 2001.

SILVA JUNIOR, A. G. Modelos assistenciais em saúde: o debate no campo da Saúde Coletiva. São Paulo: Hucitec, 2006.

SILVA, C. R.; CARRARO, L. E. A arte da sobrevivência ou sobre a vivência da arte. Interface - Comunicação, Saúde, Educação, Botucatu, v. 18, n. 48, p. 237-243, 2014. http://dx.doi.org/10.1590/1807-57622013.0890.

VASCONCELOS, M. G. F.; JORGE, M. S. B. Projeto terapêutico como dispositivo de cuidado em saúde mental. Fortaleza: UECE, 2013.

\section{Contribuição dos Autores}

Ambas as autoras foram terapeutas ocupacionais do caso clínico narrado e trabalharam conjuntamente na concepção, análise, organização e redação do texto e aprovam sua versão final.

\section{Notas}

${ }^{1}$ Conjunto de açôes teórico-práticas, político-ideológicas e éticas norteadas pela aspiração de superação do modelo manicomial. Dentre os principais referenciais teóricos da clínica psicossocial podemos citar o Materialismo Histórico, Psicanálise, Psiquiatria Democrática e a Filosofia da Diferença (COSTA-ROSA; LUZIO; YASUI, 2003).

${ }^{2}$ A Corrente criada ao final da década de 1980, por um grupo de sanitaristas do Departamento de Medicina Preventiva e Social da UNICAMP e de trabalhadores da rede de saúde de Campinas. Entre as concepçóes-chave desta proposta, citamos: a) o entendimento de que a política se realiza nos macro e micro espaços das relaçôes sociais; b) afirma o papel central dos trabalhadores para as mudanças do setor de saúde; c) preconiza a reformulaçáo do arcabouço teórico e das práticas de Saúde Pública que valorizem, em última instância, as relações intersubjetivas (CAMPOS, 1991; MERHY et al., 1991; CARVALHO, 2005; SILVA JUNIOR, 2006).

${ }^{3}$ Nome fictício para preservação da identidade do usuário. 